"This is the peer reviewed version of the following article: [International Journal of Climatology, 2013, 33 (10), pp. 2298 - 2308], which has been published in final form at

[http://dx.doi.org/10.1002/joc.3595]. This article may be used for non-commercial purposes in accordance with Wiley Terms and Conditions for Self-Archiving." 


\title{
BACKGROUND OZONE LEVEL IN THE SYDNEY BASIN: ASSESSMENT AND
}

\section{TREND ANALYSIS}

\author{
HIEP DUC $^{a^{*}}$, MERCHED AZZI $^{\mathrm{b}}$, HERMAN WAHID $^{\mathrm{c}, \mathrm{d}}$ and Q. P. HA ${ }^{\mathrm{d}}$ \\ ${ }^{a}$ Office of Environment and Heritage, NSW PO Box 29 Lidcombe, NSW 1825, Australia \\ ${ }^{b}$ CSIRO Energy Technology, Private Mail bag 7 Bangor, NSW 2234, Australia \\ ${ }^{c}$ Faculty of Electrical Engineering, Universiti Teknologi Malaysia, 81310 Skudai, Malaysia \\ ${ }^{d}$ Faculty of Engineering and Information Technology, University of Technology Sydney, Broadway, NSW 2007, Australia
}

\begin{abstract}
It has been recognized that the background ozone concentration in urban areas is changing over the years. This paper aims to determine the background ozone level using ambient air quality data measurements collected at some monitoring stations in the Sydney basin, Australia. A definition of background ozone in the context of the Sydney region is proposed. With this definition, it is possible to estimate the background ozone using ambient measurements of ozone and its precursors. The trend of the background ozone level is also estimated from the temporal ambient monitoring records as of early 1998 to 2005. These ozone level changes at different monitoring stations are assessed using the linear regression method. The results are shown to vary between different monitoring sites. This demonstrates that the local conditions at each site are important in determining as to whether an air quality management plan for reducing the ozone level to below the exceedance level is effective and achievable or not. Furthermore, the results obtained are compared with those obtained by the Clapp-Jenkin method, which is based on the relationship between oxidant and nitrogen oxides, assuming a stationary state of photochemical smog function.
\end{abstract}

KEY WORDS: background ozone, Sydney basin, ozone trend, regression, oxidant

\section{INTRODUCTION}

Background ozone level (BOL), in the context of the photochemical smog process, is known as the ozone level that is formed by purely natural processes. The concept is easily understood but the problem remains how to determine the background ozone level and distinguish between natural and anthropogenic effects. A "clean" environment, i.e. without the impact of man-made emissions, in practice, is difficult to obtain and the distinction between what is part of the natural world and what is part of the anthropogenic world by using air quality measurement data remains unclear. Such an environment also varies with changes to natural processes or events.

Clean pristine sites in the rural or bushland areas have been cited as good locations to measure the level of background ozone, which is supposed to come mostly from local natural sources and from tropospheric natural sources with a possibly stratospheric origin transported down to the surface. We can also define a local background ozone level or a global level in which the background ozone formation process is determined on a large scale at some pristine measuring sites around the globe. However, tropospheric ozone above and around a site may contain ozone and precursors with different origins, regionally or globally produced from natural or

*Correspondence to: Hiep Duc, Office of Environment and Heritage, NSW PO Box 29 Lidcombe, NSW 1825, Australia; email: Hiep.Duc@environment.nsw.gov.au 
anthropogenic sources that change over time. Thus, BOL possesses temporal and spatial factors depending on the place and period in consideration.

Oltmans et al. (2008) measured ozone levels, which they indicate as background ozone, at some remote sites from California (such as Trinidad), where the airflow patterns almost come from the Pacific Ocean and are free of contamination from North American continent. Their measurement shows that the monthly background ozone fluctuates around 35 parts per billion (ppb) for the six-year period (2002-2007) with a maximum about 50 ppb and minimum about 25 ppb. Apart from that, upon reviewing the ozone trend in Europe, Monks (2003) concludes that there is strong evidence for increasing background ozone concentration in western and northern Europe. Recently, various software packages have been used for air quality models to estimate the background ozone level. The US EPA uses the global model GEOS-CHEM to estimate the background ozone level. The estimated policy-relevant background (PRB) ozone concentrations are shown to be dependent on the season and altitude with an estimated range of 30 to $50 \mathrm{ppb}$ for typical summertime BOL of the total surface ozone concentration.

BOL is important as it sets the reference level against which anthropogenic impacts can be ascertained by the measured ozone level at a particular area. It provides the basis for human health risk assessment estimates and also determines whether policy expectations on the levels to which hourly average ozone concentrations can be lowered as a result of emission reduction requirements are realistic or not. Health risks are known to be associated with the ozone concentration in excess of the allowable background concentration. These risks can be estimated by extrapolation of exposure-response relationships down to background levels even it may be uncertain about the concentration-response relationship at lower concentrations and about whether there is evidence for the existence of a population response threshold. Epidemiological studies indicate so far that there exists no threshold of ozone level for premature mortality and other morbidity health effects (eg., exacerbation of asthma), below which there is no population response (US EPA, 2006). The BOL and its change over time therefore might be associated with human health risk. Moreover, long-term exposure to background ozone levels can also affect plant growth (Diaz-de-Quijano et al. 2009).

Our paper focuses on how to extract the background ozone level directly from the ambient air quality data by using various methods, which are mostly empirical in contrast to the modelling approach based on the ideal definition of policy-relevant background (PRB) ozone by the US EPA. Here, our approach can determine concentration values of the background ozone in a more practical manner from ambient data collected at air quality monitoring stations rather than by using the US EPA's rigorous definition. These derived values of BOL are useful in determining its temporal profile or trend so that the limit of the effectiveness of ozone control can be gauged.

In contrast to the continental scale of PRB, the derived background ozone level from ambient air quality measurements is regional in nature. We believe that sources of ozone precursors from local biogenic emission and non-local anthropogenic emission are part of the formation of background ozone. On the larger scale, BOL can also be determined by measuring ozone concentrations at pristine sites to be considered as representative of the regional or continental background ozone. But this is particularly difficult in the metropolitan area, such as Sydney (Australia) where we would like to determine its BOL (Wahid et al. 2010). This is the rationale for finding a tractable method to derive the background ozone concentration from the ambient air quality measurements as described in this paper. 
From refinements of the definition of background ozone, this paper will assess its concentration in the Sydney basin from ambient air quality data measured at several monitoring stations. As it has been recognized that the background ozone level in urban areas is changing over the years, our objective is also to derive a temporal profile of BOL in the region, and compare the results with the background ozone model obtained by using the Clapp-Jenkin method that is based on the relationship between oxidant and nitrogen oxides, assuming a photo-stationary state of smog function.

\section{BACKGROUND OZONE LEVEL DETERMINATION}

\subsection{Policy Relevant Background (PRB)}

The US EPA has defined Policy-Relevant Background (PRB) ozone concentrations used for purposes of informing decisions about National Ambient Air Quality Standards, as ozone concentrations that would occur in the absence of anthropogenic emissions, including contributions from natural sources everywhere in the world and from anthropogenic sources outside continental North America (US, Canada, and Mexico). According to US EPA (2006), “contributions to PRB ozone include photochemical actions involving natural emissions of VOCs, NOX, and CO as well as the long-range transport of ozone and its precursors from outside North America and the stratospheric-tropospheric exchange of ozone," whereby natural sources of ozone precursors are mainly biogenic emissions, wildfires, and lightning. In the 1996 ozone review, the EPA used 40 ppb as the 8-hour daily maximum background ozone level in its health risk assessment evaluations and judged that it is appropriate to estimate risks within the range of air quality concentrations down to estimated policy-relevant background level.

Abiding strictly by the definition of PRB, it is difficult to determine the PRB ozone level by using measurements obtained at various background "pristine" sites, and only a chemical transport model would be suitable to estimate the range of PRB values. Our experience of air quality modelling in the Sydney region indicates that a level of uncertainty in determining the background level for which there is no anthropogenic emission source in the region. A measurement approach combined with analytical modeling methods may provide a more tractable way to determine the background ozone level (Vigarzan, 2004; Gadner \& Dorling, 2000).

\subsection{Background ozone refinements}

Measurement at air quality monitoring sites can be used to determine the background ozone. Altshuller and Lefohn (1996) have used criteria that are enumerated and discussed for determining whether ozone concentrations at a given site can be considered to be "background" ozone. Examples of such sites are sites that receive the cleanest air mass from upwind flow off the continent or ocean or sites that are free from the influence of urban plumes. Using several techniques, the current ozone background at inland sites in the United States and Canada for the daylight 7-hour (from 09:00am to 15:59pm) seasonal (April to October) average concentrations has been shown by Altshuller and Lefohn to usually lie within the range of $35 \pm 10$ ppb. For coastal sites located in the northern hemisphere, the corresponding ozone concentrations are lower, occurring within the range of $30 \pm 5 \mathrm{ppb}$. These ranges suggest that the background ozone is somewhat dependent on a number of conditions such as the nature of upwind flow and terrain conditions, including deposition with respect to forest or agricultural areas. 
More recently, some measurement-based definitions of background ozone have appeared in the literature. According to Parrish et al. (2009), background ozone is used to qualitatively describe ozone $\left(\mathrm{O}_{3}\right)$ mixing ratios measured at a given site in the absence of strong local effects. To quantify the background ozone for the North American west coast, they used marine air ozone as measured at coastal sites in which continental influences are removed by examining wind data, trajectory and tracers.

Chan and Vet (2010) preferred the term "baseline ozone," which is used "to describe ozone mixing ratios in air masses that have not been affected by local anthropogenic precursor emissions." As mentioned therein, a measurement of ozone at a particular location can include contributions from local anthropogenic and natural precursor emissions, distant natural emissions, and distant anthropogenic emissions. These three components are included in their definition of baseline ozone. To quantify the baseline ozone across the North American continent, from ozone data measured at non-urban sites, they use the principal component analysis to group sites forming specific geographic regions for baseline ozone, and then backward air parcel trajectory clustering to result in the six trajectory clusters of air parcels for each site. The baseline trajectory cluster was chosen as the one having the lowest 95th percentile ozone among the six clusters. According to the authors, the 95th value is predominately associated with long-range transport for remote locations, while lower percentile values (such as median or 75th percentile) are affected by dry deposition and NO scavenging. Thus, the chosen cluster represents baseline air flow with the least influence of regional and local-scale photochemically-produced ozone.

\subsection{Nighttime and daytime background ozone level}

Policy relevant background ozone, as defined by US EPA, which excludes ozone formation contribution from outside the continent is rather difficult or impossible to measure and can only be determined by modelling. In this paper we are concerned with assessing BOL in a practical way considering the nighttime nonphotochemical condition and daytime photochemical condition. Here, ambient air quality measurements are used to estimate the background ozone concentration, taking into account local site conditions. The background ozone level in a local (e.g. in the Sydney basin) or regional area is defined as the ozone level which would be measured if there were no ozone precursor anthropogenic source emissions within that area. This definition helps in our understanding of background ozone, its local, regional and global evolution, and in the determination of its concentration and temporal profile, which can be useful to policy maker. Notably, the proposed background ozone definition can also allow for BOL estimation by using a modelling method only or in combination with observations at remote clean sites.

There are a number of estimated background ozone levels of interest, which can be calculated (1-hour daily maximum, 8-hour daily maximum and daily average) using the hourly ambient air quality data at the stations, mostly in summer being the period of interest during a year. In this work we consider not only the daytime but also nighttime background ozone level. Nighttime background ozone is defined as the average of ambient measurements of hourly ozone values from night time to early morning (i.e. from 19:00pm to 08:00am the next morning), when there is no nitric oxide present for at least 2 hours consecutively (Duc and Azzi, 2009). This prevents the reaction of ozone with nitric oxide (i.e. NO scavenging of ozone). This definition of nighttime background ozone allows for excluding the photochemical process that would occur during daytime, in which both natural and anthropogenic sources are present. Thus, it includes apparently the case of no ozone loss due to 
scavenging $(\mathrm{NO}=0)$ as if only natural precursor but no anthropogenic sources were present in the local area. Here nitrogen oxide is assumed to be a surrogate for the presence of anthropogenic sources and ozone deposition loss is not accounted for. This nighttime background ozone can generally include ozone formed from precursor emission from natural and anthropogenic sources inside and outside the area. From our understanding of Sydney meteorology, residual ozone formed during the day is mostly carried off-shore by westerly wind and drainage flow from the mountains during nighttime to early morning. Hence it is expected that the nighttime background ozone does not contain much ozone formed previously in the area.

It is recognized that a better way for determination of background ozone level should include also the daytime photochemical process when only natural sources are present locally. For this purpose, the regression and extrapolation method as proposed by Clapp and Jenkin (2001) can be used to estimate the daytime background ozone. In this paper, we consider both, i.e. using data collected from evening to early morning to find nighttime background ozone when $\mathrm{NO}=0$, and using the Clapp-Jenkin method to determine daytime background oxidant level.

The background ozone level determined in this paper is qualitatively similar to the baseline levels and trends of ground level ozone described in Chan and Vet (2010), and the ozone in marine boundary layer inflow presented in Parrish et al. (2009) as the results obtained are all based on measurements at monitoring sites. The main difference here is in the spatial scale, quantitatively. Our results on urban background ozone are locally derived while Chan and Vet's baseline ozone is regionally derived for North America, and Parrish et al. background ozone is based on marine ozone airflow coming to continental North American west coast at suitable monitoring sites (which can include ozone from across the Pacific Ocean in North Asia).

\section{BACKGROUND OZONE TREND AND ANALYSIS IN THE SYDNEY BASIN}

\subsection{Measurement data}

The New South Wales Office of Environment and Heritage (OEH) operates a comprehensive air quality monitoring network throughout the state, focused on the three main population: metropolitan Sydney, the Lower Hunter (north of Sydney) and the Illawarra (south of Sydney), as depicted in Figure 1. As a result of the Metropolitan Air Quality Study (MAQS), which was initiated in 1992, the number of monitoring stations was significantly increased as well as the number of air pollutants and meteorological parameters to be measured.

The Sydney basin currently has 14 monitoring stations scattered throughout the Sydney metropolitan region, from the coastal area in the East to the edge of the Blue Mountain in the North West and in the West. Meteorology in the basin follows a general pattern. In the morning after sunrise, onshore sea breeze flow from the east and north east flowing across Sydney toward the south west causes an elevated level of ozone in the south west and west of Sydney in the afternoon (Hart et al. 2006). In the evening and nighttime, drainage flow of cold air from the mountains in the west is directed to the coastal east and from south west to the north. It has been known that chemical transport of nitrogen oxides $\left(\mathrm{NO}_{\mathrm{x}}\right)$ and ozone also occur between the three regions, from the lower Hunter to the Sydney basin and from the Sydney basin to the Illawarra.

For the background ozone study, three monitored air pollutants data are used, namely ozone $\left(\mathrm{O}_{3}\right)$, nitric oxide (NO) and nitrogen dioxide $\left(\mathrm{NO}_{2}\right)$. These pollutants are generally measured in part per billion (ppb) units on an hourly basis. The ozone data are measured using the Ecotech Ozone Monitor 9810 which is based on the ultraviolet spectroscopy principle. Equipment used as gas analysers to measure the nitrogen oxides $\left(\mathrm{NO}_{\mathrm{x}}\right)$ 
includes Ecotech 9841, API Model T200E and Thermal Instrument TEI 42i, which are installed at all Sydney network air quality monitoring sites. All instruments for capturing particulate air samples, and gas analyzer monitoring equipment are subject to frequent calibration and consistency checks, in which typically the zero calibration and full scale calibration are automatically performed every day in the early morning after midnight.

\subsection{Estimated daily nighttime background ozone}

From the proposed nighttime background ozone definition and data collected at a number of different monitoring sites in the Sydney region, a statistical summary of the background ozone concentration is given in Table 1 , where the $1^{\text {st }}$ quartile, median $\left(2^{\text {nd }}\right.$ quartile $), 3^{\text {rd }}$ quartile and statistical average are shown for each station. These stations are mostly urban sites (except Vineyard and Richmond, located in the semi-rural or suburban area), where ozone concentration data were being collected over the period of 1998 to 2005 .

Table 1 shows a statistical summary in the $1^{\text {st }}$ quartile, median, $3^{\text {rd }}$ quartile and average, in parts per billion (ppb), of the background ozone level distributions at thirteen sites of the Sydney basin. It is noted that the statistical properties of BOL distributions were different between regions and within a region, and that BOL in the East and North West of Sydney in general was a higher than in the West and South West of Sydney. A possible reason for this is that during nighttime and early morning, North West Sydney is downwind from the South West due to southerly flow and Eastern Sydney is downwind from the westerly drainage flow from the mountains in the west of the Sydney basin.

\subsection{Nighttime background ozone trend}

In theory, excluding all anthropogenic sources in the region and Australia wide, the average background ozone level in Sydney should be stable with respect to time. It is however possible that not only the emission of precursors outside the Sydney region, but also global emissions outside Australia or other mechanisms such as climate-induced changes could also influence the level of background ozone over the time. It is therefore beneficial to study the BOL change in the Sydney region, as derived from ozone measurements at various monitoring sites, in the temporal domain.

The trend of the nighttime background ozone can be found, using nighttime hourly ozone monitoring data collected from the period of 1998 to 2005 at various monitoring stations in the Sydney basin. To analyze all hourly ozone data, the linear regression method was used with ozone as an affine function of nitrogen oxide and the BOL is derived when the NO concentration is zero. Figure 2 shows an example of the results for St Marys site, a suburban site in the west of Sydney. It reveals an increasing trend with an increasing rate in the ozone concentration of $3.2 \pm 0.3 \mathrm{ppb}$ (standard error is $0.3 \mathrm{ppb}$ ) over the 1998 to 2005 period (or $0.43 \pm 0.04$ ppb per year) with a zero probability ( $\mathrm{p}$-value) obtained for the null hypothesis of the slope and an intercept of $15.6 \pm 0.2 \mathrm{ppb}$ in the linear regression trend line, as shown in Figure 2(a).

Considering the level of oxidant, which consists of ozone $\left(\mathrm{O}_{3}\right)$ and nitrogen dioxide $\left(\mathrm{NO}_{2}\right)$, a similar upward trend can be observed as shown in Figure 2 (b) with an increase of $4.6 \pm 0.3$ ppb over the same period and intercept of $20.1 \pm 0.2 \mathrm{ppb}$ in the linear regression trend line. Again the p-value is 0 for zero slope, and the oxidant concentration exhibits an increase on an average of $0.66 \pm 0.04 \mathrm{ppb}$ per year.

The same trend is found in our analysis for all other sites in the Sydney basin, except at Lidcombe where the Lidcombe monitoring site was discontinued in mid 2002 and was replaced by a nearby station, a few streets 
away at Chullora. With a possible extension of data points up to 2005 using data collected at Chullora, a similar temporal profile could be obtained at Lidcombe in comparison to other stations.

As summer is the time when photochemistry is most active, only ozone data during that time of the year rather than of the whole year are used to determine BOL (Fiore et al., 2002). Indeed, our results show that there is not much difference in the trend lines from using only summer data and using all yearly data.

The Sydney background ozone trend is similar to the trend in US and Europe. Indeed, Jaffe and Ray (2007) has reported similarly of the ozone trend at 11 remote rural sites in north and western US (including Alaska), in which 7 sites show a statistically significant increase in ozone with an annual increase of $0.26 \mathrm{ppb}$ on average. These sites are considered as 'pristine' background ozone sites. Temperature changes can account for only part of the trend, and the authors explained these trends coming possibly from increasing regional emissions, change in the distribution of emissions, increasing biomass burning or increasing global background ozone, and especially due to rapid growth in emissions within North East Asia. In the same context, Simmonds et al. (2004) shows an increasing trend in background ozone observations at Mace Head on the west coast of Ireland from 1987 to 2003 with an average of $0.49 \pm 0.19 \mathrm{ppb}$ per year. They concluded that there has been at least one major perturbation of the ozone trend during the 1998-1999 timeframe that was associated with global biomass burning coupled to an intense El Nino event of 1997.

\section{RELATIONSHIP BETWEEN OXIDANT AND NITROGEN OXIDES IN BACKGROUND OZONE MODELLING}

In the attempt to determine the BOL in the daytime photochemical condition and its trend from ambient measurements at local site conditions, this section describes the relationship between oxidant (including ozone and nitrogen dioxide, $\left.\mathrm{O}_{3}+\mathrm{NO}_{2}\right)$ and nitrogen oxides $\left(\mathrm{NO}_{\mathrm{x}}=\mathrm{NO}+\mathrm{NO}_{2}\right)$ at various sites in the Sydney basin. The results obtained from the measurements, observed locally or regionally, can be extrapolated to find the derived background ozone at the local sites. Motivated by Clapp and Jenkin (2001), we will focus on establishing a linear relationship between the average values of oxidant and $\mathrm{NO}_{\mathrm{x}}$ levels from daily data collected respectively in daytime and nighttime. Also, this oxidant level at a given location is made up of $\mathrm{NO}_{\mathrm{x}}$-independent and $\mathrm{NO}_{\mathrm{x}}$ dependent contributions. The $\mathrm{NO}_{\mathrm{x}}$-independent contribution is the intercept, which equals the daytime background oxidant level, while the slope of the regression line represents the $\mathrm{NO}_{\mathrm{x}}$-dependent contribution or the level of primary pollution from the local sources. The analysis has covered the six-year period from 1998 to 2003, collected in the Sydney region during the photochemistry-active summer in the southern hemisphere.

This approach of using the regression line to find the BOL is also similar to the one that Altshuller and Lefohn (1996) but instead of using the relationship between ozone and peroxyacetyl nitrate (PAN) as well as ozone versus total reactive nitrogen species (NOy) or ozone versus (NOy -NOx), we use the relationship between oxidant (ozone+nitrogen dioxide) versus NOx as outlined by Clapp and Jenkin (2001). The reason is that most ambient monitoring stations do not measure PAN or NOy and this situation is the case in the Sydney basin.

\subsection{Local background oxidant level analysis}

Using data for the summer 1998 period at monitoring sites in the Sydney basin, the plots of daylight average $\left(\mathrm{O}_{3}+\mathrm{NO}_{2}\right)$ versus $\mathrm{NO}_{\mathrm{x}}$ are shown in Figure 3 respectively for Blacktown, Bringelly, St Marys and 
Richmond. Most of these sites are considered as urban except for Richmond, which is located in a semi-rural area. A linear regression line can be fitted to the corresponding data as shown but some variance can be expected. This is explained by a major variation in the regional contributions resulting from frequent elevated levels of ozone during the summer period. Two separate regression lines can be fitted to the 'ozone nonepisode' and 'ozone episode' days (Clapp and Jenkin, 2001). Here, the episode day is defined as a day when one or more stations in the Sydney basin has an ozone level greater than 80 parts per billion (ppb). The daytime background level for 'non-episode' and 'episode' days can be obtained from the intercepts of the regression lines.

As shown in Figure 3, various slopes of the regression lines for the episode and non-episode daytime oxidant level appear at most of the sites. If the slopes are similar, e.g. at Bringelly site, it is suggested that the local contribution of nitrogen oxides to the oxidant level ( $\mathrm{NO}_{\mathrm{x}}$-dependent) is the same at that site during episode and non-episode days. Thus, only the daytime background level ( $\mathrm{NO}_{\mathrm{x}}$-independent) is different with a higher concentration value being obtained for episode days. The derived background oxidant levels at the four sites in the Sydney West, as presented in Figure 3, range from 27 to $46 \mathrm{ppb}$ for episode days and from 15 to 27 ppb for non-episode days. Notably, the results are similar to those derived by Clapp and Jenkin (2001) using ambient air quality data measured at rural and urban sites in the UK. Their background oxidant level is about $35 \mathrm{ppb}$ for non-episode days and about $55 \mathrm{ppb}$ for episode ones. These values can be compared with the BOL value of about $35 \mathrm{ppb}$ as reported by Oltmans et al. (2008) of air entering the west coast of the North America at Trinidad.

Contrary to the findings using ambient data measured at Sydney West sites, the overall analysis for East Sydney sites, such as Randwick and Rozelle, does not show a distinct relation between oxidant $\left(\mathrm{O}_{3}\right.$ and $\left.\mathrm{NO}_{2}\right)$ and nitrogen oxides $\left(\mathrm{NO}_{\mathrm{X}}\right)$ and the scatter around the regression lines appears to be relatively large. Under the photo-stationary assumption for photochemical reactions, it is generally expected a linear relationship between oxidant and nitrogen oxide levels. This means the ideal photo-stationary state of smog reaction rarely occurs in the East Sydney area.

Similar analysis was conducted with the 1999 summer data, covering three different regions in the Sydney basin, i.e western, eastern and central Sydney. The daytime background levels of oxidant for non-episode and episode days obtained from the intercepts of the regression lines are summarized in Table 2, where the local oxidant contributions are illustrated by the rate of change in background oxidant level with respect to the $\mathrm{NO}_{\mathrm{X}}$ concentration (slope). In average, the derived background oxidant for the Sydney area is about 16 ppb for nonepisode days and about 4 ppb higher for the episode days. Generally, the daytime background ozone level was more consistent during the non-episode days because it has a small change between $10 \mathrm{ppb}$ to $20 \mathrm{ppb}$ while for episode days, the level varies from $11 \mathrm{ppb}$ to $37 \mathrm{ppb}$. However, only few sites like St Marys, Bargo, Randwick and Liverpool display a clear relationship for the local contribution of the oxidant level ( $\mathrm{NO}_{\mathrm{x}}$-dependent) in this year, as the slopes for regression lines between non-episode and episodes days are about similar. This implies that the local oxidant level depended on the local activities and pollution emissions, thus its trends varied from site to site and also between episode and non-episode days. It is also noted that the $\mathrm{NO}_{\mathrm{x}}$-dependent contribution apparently existed at the semi-rural inland sites such as Vineyard, Richmond and Bringelly (with higher value of slopes). The reason was probably due to the long range transportation of the ozone produced due to emission from the industrial activities and vehicle transports in the coastal area to these inland sites. 
Table 3 shows the derived results for background oxidant level in the year 2000. On average, the nonepisode level was $3 \mathrm{ppb}$ higher than the previous year. However, there were not much changes in the level for the episode days. Furthermore, the local contributions also followed similar trends as in year 1999 but with slightly higher values. A clear oxidant- $\mathrm{NO}_{\mathrm{X}}$ relationship between episode and non-episode days can be observed at St Marys and Bargo (in the West Sydney), Randwick, Earlwood and Woolooware (in the East Sydney), and Liverpool (in the central of Sydney). Nevertheless, the results for these three years 1998-2000 show that the ideal photo-stationary state cannot be achieved at every site due to some variations of the local contributions, especially during the episode days.

In the subsequent five-year analysis from 2001 to 2005, we focus on the $\mathrm{NO}_{\mathrm{X}}$-independent contributions. From Table 4, the upward tendency of the daytime background oxidant level did occur generally for the nonepisode days, except for Westmead and Linfield (in the central part of Sydney). For the episode days, there were some sites that show an upward trend such as Bringelly, Bargo and Vineyard, all located at the west of Sydney, and are consistent with the findings stated above. However, the background oxidant level at some other sites was observed to vary irregularly for each year.

\subsection{Background oxidant level trend}

The overall trend of the background oxidant level for non-episode days at a number of monitoring sites in the Sydney basin for the period from 1998 to 2005 is shown in Figure 4. Therein, an upward trend can be seen almost for each site except for Richmond, where a higher value of the average concentration is observed in the beginning year of the period under investigation. The average trend shown in the figure is computed by considering the values from several monitoring sites in Sydney during the corresponding year of the period. On average, the same upward trend appears for the non-episode days, as can be seen in Figure 5. However, some sites show no clear trend for the daytime background levels of oxidant (e.g. at Randwick and Rozelle in Eastern Sydney), in which the concentration values were fluctuating year by year. It implies that the estimation of BOL by using the Clapp-Jenkin (C-J) method is more suitable for analysis during non-episode days rather than episode days. In addition, the regression analysis is more comprehensive by using data of the oxidants and nitrogen oxides for the entire basin rather than considering the individual regression analysis for each site.

The overall comparison for the defined background ozone level for 1998-2005 data (e.g. for St Marys site) using several methods is now summarized in Table 5. It is clear that methods 2 and 3 show similar level of the nighttime and daytime background oxidant, however, higher values occurred in 2004 and 2005 using the C-J method. This partially confirms the validity of our proposed approach for the determination of background ozone level. Furthermore, the annual BOL increase (in ppb/yr) by using the C-J linear trend line is slightly higher whereas a consistent trend is observed by the proposed methods 1 and 2. As shown, an offset of about 5 ppb exists consistently between the nighttime background ozone and the nighttime oxidant $\left(\mathrm{O}_{3}+\mathrm{NO}_{2}\right)$ to account for the nitrogen dioxide concentration.

On a larger scale, the upward trend may be explained as due to the increasing global emission of ozone precursors, especially in North Asia in recent years. The link between a local BOL and a continental source of emission has been suggested by Derwent et al. (2008), who used a global chemical transport model, STOCHEM, to show that $\mathrm{NO}_{\mathrm{x}}$ emission pulses emitted in one continent (e.g., North America or Asia) can generate surface ozone in another (e.g. Europe) via the transport of precursors and ozone into the troposphere 
and then the mixing down of the air above to the surface level. On a continental scale, Oltmans et al. (2006) recorded a slight increase in surface ozone per year at some (but not all) locations of the world and they also emphasized the importance of the relative contribution of the stratosphere to tropospheric ozone. Notably, the upward trend reported in this paper for the local BOL in Sydney is also in line with the results obtained by Jaffe and Ray (2007) in the US and by Simmonds et al. (2004) in Europe.

Currently, the ozone standards for one-hourly average and four-hourly average ozone concentrations in Australia are $100 \mathrm{ppb}$ and $80 \mathrm{ppb}$ respectively. In the Sydney basin, there are several exceedances above the one-hourly standard each year. Efforts have been made to reduce the number of exceedances through emission control of motor vehicles, domestic and commercial sources of oxides of nitrogen $\left(\mathrm{NO}_{\mathrm{x}}\right)$ and Volatile Organic Compounds (VOCs) notwithstanding the increase of population and the number of motor vehicles in the basin. Most ozone level exceedances have occurred in the West, North West and South West with a relatively higher BOL in Sydney North West compared to other parts of Sydney.

\section{DISCUSSION AND CONCLUSION}

This paper has presented some refinements of the BOL definition and presented measurement-based methods to determine the nighttime and daytime background ozone level. The nighttime BOL as the average of ambient measurements of hourly ozone values from nighttime to early morning when NO is not present for at least 2 hours consecutively. Ambient air quality data collected at monitoring sites in the Sydney basin are used to derive the local BOL and to investigate the BOL trend over the years. The nighttime BOL results have been compared with a method to estimate the background oxidant concentration introduced by Clapp and Jenkin (2001).

The nighttime BOL as defined and derived in this paper is shown to be suitable to the Sydney basin. This is owing to its meteorological condition that causes some residual photochemical smog air formed locally in the Sydney region during the daytime to be shifted off-shore during nighttime by the westerly flow from the mountains in the west. Admittedly, there is always some residual photochemical-produced from anthropogenic sources within the Sydney region that cannot be filtered out completely. However, in the absence of a better empirical method to find the background ozone level, the night-time BOL proposed in this paper is useful due to its consistency in the trend of night-time BOL with the trend of derived daytime BOL by using the Clapp \& Jenkin method. The derived night-time BOL data are hourly data while daytime BOL derived from the Clapp \& Jenkin method is on an aggregated time scale such as monthly, seasonally or yearly values.

From the analysis, there is a clear upward trend in background ozone concentration at nearly all Sydney monitoring sites. For other regions, such as the Lower Hunter in the north and Illawarra in the south of the Sydney basin, the BOL and their trends can be determined and the results may be different from that of Sydney as the BOL (and hence its trend) is depending on a number of conditions such as the meteorological flow, pollution sources and terrain conditions in those regions. Altshuller and Lefohn (1996) derived BOL at many different coastal and inland sites in the United States and Canada. They found that the concentration of background ozone varies as a function of geographic area, elevation, season, and averaging time. They also suggested that the different ranges of derived BOL is accounted for by the BOL's dependence on a number of conditions such as the nature of upwind flow, lack of pollution sources and terrain conditions including deposition with respect to forest or agricultural areas at those sites. 
From the local or regional scale, considerations can be made to the background ozone on a continental scale and hence the result of background ozone trend in this paper may be compared and related to the trend in the background ozone observation measured at Cape Grim, in Tasmania (Australia). Cape Grim is located at the southern end of the Australian continent and is mostly unaffected by anthropogenic sources. There is a strong coupling of surface ozone at Cape Grim and the troposphere ozone during the winter months. An increasing trend of background ozone at Cape Grim from 1982 to 2003 is detected from about 24 ppb to 26 ppb (Galbally et al, 2005). As suggested by Oltmans et al. (2006), changes in air mixed down from the troposphere above to the surface could play a role in the change of ozone seen at Cape Grim in the mid latitude southern hemisphere. This upward trend in background ozone at Cape Grim is also in line with results reported in the US by Jaffe \& Ray (2007) and in Europe by Simmonds et al. (2004).

The implication of this background ozone trend is believed to be important for the regulatory authorities in many countries in setting the ozone goal and target for emission reduction, as it may be not possible to act independently in the local and regional context without a coordinated action on the global scale to reduce also the emission of precursors. For example, if the current 1-hour ozone standard is lowered it would mean that the efforts and policy measures for reduction of the annual number of exceedance in the Sydney region can be less effective and it would be more difficult to keep the ozone level within the allowable threshold.

\section{REFERENCES}

Altshuller AP, Lefohn AS. 1996. Background ozone in the planetary boundary layer over the United States. Journal of Air and Waste Management Association 46(2): 134-141.

Chan E, Vet RJ. 2010. Baseline levels and trends of ground level ozone in Canada and the United States. Atmos. Chem. Phys. 10: 8629-8647.

Clapp L, Jenkin M. 2001. Analysis of the relationship between ambient levels of $\mathrm{O}_{3}, \mathrm{NO}_{2}$ and $\mathrm{NO}$ as a function of $\mathrm{NO}_{\mathrm{x}}$ in the UK. Atmospheric Environment 35: 6391-6405

Derwent RG, Stevenson DS, Doherty RM, Collins WJ, Sanderson MG. 2008. How is surface ozone in Europe linked to Asian and North American $\mathrm{NO}_{\mathrm{x}}$ emission. Atmospheric Environment 42: 7412-7422.

Diaz-de-Quijano M, Penuelas J, Ribas A. 2009. Increasing interannual and altitudinal ozone mixing ratios in the Catalan Pyrenees. Atmospheric Environment 43: 6049-6057.

Duc H, Azzi M. 2009. Analysis of background ozone in the Sydney basin. Proceedings of the 18th World IMACS/MODSIM 2009 International Congress on Modelling and Simulation, Cairns Australia: 2307-2313. http://www.mssanz.org.au/modsim09/F10/duc.pdf

Fiore AM, Jacob DJ, Bey I, Yantosca RM, Field BD, Fusco AC. 2002. Background ozone over the United States in summer: Origin, trend, and contribution to pollution episodes. J. of Geophysical Research 107: 11.1-11.25.

Hart M., de Dear, R., Hyde R., 2006. A symnoptic climatology of tropospheric ozone episodes in Sydney, Australia. Int. J. Climatol. 26: 1635-1649.

Jaffe D, Ray J. 2007. Increase in surface ozone at rural sites in the western US. Atmospheric Environment 41: 5452-5463.

Gadner MW, Dorling SR. 2000. Statistical surface ozone models: an improved methodology to account for non-linear behaviour. Atmospheric Environment 34: 21-34.

Gabally, I., Meyer, C. Bentley S., 2005, Trends in near-surface ozone at Cape Grim and in the Southern Hemisphere troposphere [electronic publication], In: Towards a new agenda: 17th International Clean Air \& Environment Conference proceedings, Hobart, Clean Air Society of Australia and New Zealand 
Monks PS. 2003. TROTREP-Tropospheric ozone and precursors, trends, budgets and policy, synthesis and integration report. Report to the EU FPV Energy, Environment and Sustainable Development Program, European Union.

http://www.le.ac.uk/chemistry/atmospheric/pub.html

Simmonds P, Derwent R, Manning A, Spain G. 2004. Significant growth in surface ozone at Mace Head, Ireland, 19872003. Atmospheric Environment 38: 4769-4778.

Oltmans S, Lefohn A, Harris J, Galbally I, Scheel HE, Bodeker G, Brunke E, Claude H, Tarasick D, Johnson BJ, Simmonds P, Shadwick D, Anlauf K, Hayden K, Schmidlin F, Fujimoto T, Akagi K, Meyer C, Nichol S, Davies J, Redondas A, Cuevas E. 2006. Long-term changes in troposphere ozone. Atmospheric Environment 40: 3156-3173.

Oltmans SJ, Lefohn A, Harris J, Shadwick D. 2008. Background ozone levels of air entering the west coast of the US and assessment of long-term changes. Atmospheric Environment 42: 6020-6038.

Parish DD, Millet DB, Goldstein AH. 2009. Increasing ozone in marine boundary layer inflow at the west coasts of North America and Europe. Atmos. Chem. Phys. 9: 1303-1323.

U.S. Environmental Protection Agency. 2006. Air quality criteria for ozone and related photochemical oxidants (final). Research Triangle Park, NC: Office of Research and Development, EPA/600/R-05/004af. http://cfpub.epa.gov/ncea/cfm/recordisplay.cfm?deid=149923

U.S. Environmental Protection Agency. 2007. Review of the National Ambient Air Quality Standards for Ozone: Policy Assessment of Scientific and Technical Information OAQPS Staff Paper. Research Triangle Park, NC: Office of Air Quality and Planning and Standards, EPA-452/R-07-003.

www.epa.gov/ttn/naaqs/standards/ozone/data/2007_01_ozone_staff_paper.pdf

Vingarzan R. 2004. A review of surface ozone background levels and trends. Atmospheric Environment 38: 3431-3442.

Wahid H., Ha, Q.P., Duc, H., 2010. A Metamodel for Background Ozone Level Using Radial Basis Function Neural Networks. IEEE Int. Conf. Control Automation Robotics and Vision, Singapore, 2010: 958-963.

\section{TABLES}

Table 1. Statistics of non-photochemical nighttime background ozone at monitoring sites in the Sydney region

\begin{tabular}{|c|c|c|c|c|c|c|}
\hline Region & Site & Period & $\begin{array}{c}1^{\text {st }} \text { Quartile } \\
\text { (ppb) }\end{array}$ & $\begin{array}{c}\text { Median } \\
\text { (ppb) }\end{array}$ & $\begin{array}{c}3^{\text {rd }} \text { Quartile } \\
\text { (ppb) }\end{array}$ & $\begin{array}{c}\text { Average } \\
\text { (ppb) }\end{array}$ \\
\hline \multirow{4}{*}{$\begin{array}{l}\text { Sydney East } \\
\text { (urban) }\end{array}$} & Woolooware & $01 / 01 / 1998$ to $30 / 08 / 2004$ & 16 & 21 & 25 & 21 \\
\hline & Rozelle & $01 / 07 / 1998$ to $17 / 11 / 2005$ & 13 & 18 & 22 & 18 \\
\hline & Earlwood & $01 / 02 / 1998$ to $17 / 11 / 2005$ & 15 & 19 & 23 & 19.2 \\
\hline & Lindfield & $01 / 01 / 1998$ to $11 / 02 / 2005$ & 12 & 17 & 22 & 17.2 \\
\hline \multirow{2}{*}{$\begin{array}{l}\text { South West } \\
\text { (suburban) }\end{array}$} & Bringelly & $01 / 01 / 1998$ to $18 / 11 / 2005$ & 10 & 17 & 25 & 17.7 \\
\hline & Liverpool & $01 / 01 / 1998$ to $17 / 11 / 2005$ & 12 & 19 & 25 & 18.8 \\
\hline \multirow{3}{*}{$\begin{array}{l}\text { Sydney West } \\
\text { (urban) }\end{array}$} & Westmead & $01 / 01 / 1998$ to $06 / 08 / 2004$ & 11 & 15 & 20 & 16 \\
\hline & St Marys & $01 / 01 / 1998$ to $18 / 11 / 2005$ & 11 & 17 & 22 & 17.2 \\
\hline & Lidcombe & $01 / 01 / 1998$ to $01 / 05 / 2002$ & 11 & 16 & 22 & 16.9 \\
\hline
\end{tabular}

Table 2. Comparison between episode and non-episode background oxidant levels at Sydney basin sites in 1999

\begin{tabular}{llcc|cc}
\hline \multirow{2}{*}{ Region } & \multirow{2}{*}{ Site } & \multicolumn{2}{c|}{ Non-episode } & \multicolumn{2}{c}{ Episode } \\
\cline { 3 - 6 } & & Background level $(\mathbf{p p b})$ & Slope & Background level (ppb) & Slope \\
\hline \multirow{2}{*}{ West } & Blacktown & 15 & 0.65 & 16 & 1.95 \\
& Bringelly & 16 & 0.95 & 14 & 2.25 \\
& St Marys & 21 & 0.40 & 37 & 0.70 \\
& Richmond & 18 & 0.75 & 11 & 3.70 \\
\hline
\end{tabular}




\begin{tabular}{|c|c|c|c|c|c|}
\hline & Bargo & 13 & 0.45 & 32 & 0.60 \\
\hline & Vineyard & 17 & 1.15 & 17 & 3.10 \\
\hline \multirow[t]{4}{*}{ Eastern } & Randwick & 16 & 0.40 & 21 & 0.65 \\
\hline & Rozelle & 10 & 0.40 & 13 & 0.85 \\
\hline & Earlwood & 13 & 0.35 & 17 & 0.80 \\
\hline & Woolooware & 16 & 0.50 & 17 & 1.15 \\
\hline \multirow[t]{5}{*}{ Central } & Lidcombe & 16 & 0.40 & 23 & 1.25 \\
\hline & Westmead & 13 & 0.40 & 13 & 1.40 \\
\hline & Liverpool & 16 & 0.50 & 28 & 0.70 \\
\hline & Lindfield & 18 & 0.30 & 18 & 2.10 \\
\hline & Average & 15.5 & 0.54 & 19.8 & 1.51 \\
\hline
\end{tabular}

Table 3. Comparison between episode and non-episode background oxidant levels at Sydney basin sites in 2000

\begin{tabular}{|c|c|c|c|c|c|}
\hline \multirow{2}{*}{ Region } & \multirow{2}{*}{ Site } & \multicolumn{2}{|l|}{ Non-episode } & \multicolumn{2}{|l|}{ Episode } \\
\hline & & Background level (ppb) & Slope & Background level (ppb) & Slope \\
\hline \multirow[t]{6}{*}{ West } & Blacktown & 18 & 0.65 & 17 & 1.85 \\
\hline & Bringelly & 16 & 1.45 & 15 & 2.25 \\
\hline & St Marys & 22 & 0.40 & 37 & 0.75 \\
\hline & Richmond & 21 & 0.85 & 10 & 3.80 \\
\hline & Bargo & 21 & 0.85 & 32 & 0.65 \\
\hline & Vineyard & 22 & 0.45 & 18 & 3.10 \\
\hline \multirow[t]{4}{*}{ Eastern } & Randwick & 20 & 0.50 & 21 & 0.60 \\
\hline & Rozelle & 18 & 0.40 & 13 & 0.85 \\
\hline & Earlwood & 18 & 0.50 & 17 & 0.85 \\
\hline & Woolooware & 15 & 1.15 & 17 & 1.10 \\
\hline \multirow[t]{5}{*}{ Central } & Lidcombe & 19 & 0.45 & 22 & 1.30 \\
\hline & Westmead & 16 & 0.60 & 13 & 1.40 \\
\hline & Liverpool & 21 & 0.35 & 28 & 0.65 \\
\hline & Lindfield & 19 & 0.40 & 18 & 2.10 \\
\hline & Average & 19.0 & 0.64 & 19.9 & 1.52 \\
\hline
\end{tabular}

Table 4. Episode and non-episode background oxidant levels at Sydney basin sites from 2001 to 2005

\begin{tabular}{|c|c|c|c|c|c|c|c|c|c|c|c|}
\hline \multirow{2}{*}{ Region } & \multirow{2}{*}{ Site } & \multicolumn{5}{|c|}{ Non-episode background level (ppb) } & \multicolumn{5}{|c|}{ Episode background level (ppb) } \\
\hline & & 2001 & 2002 & 2003 & 2004 & 2005 & 2001 & 2002 & 2003 & 2004 & 2005 \\
\hline \multirow[t]{6}{*}{ West } & Blacktown & 22 & 23 & 24 & $*$ & * & 30 & 20 & 24 & * & * \\
\hline & Bringelly & 21 & 21 & 19 & 32 & 37 & 15 & 32 & 32 & 50 & 56 \\
\hline & St Marys & 22 & 24 & 23 & 39 & 38 & 22 & 19 & 33 & 53 & 57 \\
\hline & Richmond & 21 & 26 & 25 & 38 & 38 & 35 & 24 & 26 & 45 & 55 \\
\hline & Bargo & 20 & 23 & 21 & 27 & 31 & 19 & 29 & 32 & 44 & 45 \\
\hline & Vineyard & 27 & 25 & 29 & 38 & 38 & 17 & 18 & 28 & 43 & 42 \\
\hline \multirow[t]{4}{*}{ Eastern } & Randwick & 21 & 21 & 22 & 20 & 24 & 25 & 28 & 23 & 22 & 22 \\
\hline & Rozelle & 21 & 20 & 20 & 20 & 20 & 25 & 20 & 17 & 38 & 27 \\
\hline & Earlwood & 20 & 19 & 20 & 20 & 24 & 21 & 21 & 21 & 53 & 50 \\
\hline & Woolooware & 20 & 19 & 21 & $*$ & $*$ & 21 & 20 & 27 & $*$ & $*$ \\
\hline \multirow[t]{5}{*}{ Central } & Lidcombe & $*$ & * & $*$ & $\begin{array}{c}30 \\
\text { (Chullora) }\end{array}$ & $\begin{array}{c}33 \\
\text { (Chullora) }\end{array}$ & * & $*$ & * & $\begin{array}{c}49 \\
\text { (Chullora) }\end{array}$ & $\begin{array}{c}52 \\
\text { (Chullora) }\end{array}$ \\
\hline & Westmead & 24 & 18 & 22 & $*$ & $*$ & 29 & 13 & 23 & $*$ & $*$ \\
\hline & Liverpool & 24 & $*$ & 17 & 20 & 35 & 27 & - & 15 & 58 & 58 \\
\hline & Lindfield & 25 & 18 & 22 & 30 & $*$ & 33 & 25 & 37 & 60 & $*$ \\
\hline & Average & 22.2 & 21.4 & 21.9 & 28.5 & 31.8 & 24.5 & 22.4 & 26.0 & 46.8 & 46.4 \\
\hline
\end{tabular}

Asterisk $\left({ }^{*}\right)$ represents the non-available data for the correspondence year.

Table 5. Background ozone level determination (in ppb) at St Marys using several methods

\begin{tabular}{cccccccccccc}
\hline & Methods & & 1998 & 1999 & 2000 & 2001 & 2002 & 2003 & 2004 & 2005 & $\begin{array}{c}\text { Trend } \\
(\mathbf{p p b} / \mathrm{yr})\end{array}$ \\
\hline $1 \quad \begin{array}{l}\text { Nighttime background ozone } \\
\text { average night-time when NO=0) }\end{array}$ & (daily & 15.6 & 16.0 & 16.5 & 16.9 & 17.3 & 17.8 & 18.2 & 18.6 & +0.43 \\
\hline
\end{tabular}




$2 \begin{aligned} & \text { Nighttime background oxidant (daily } \\ & \text { average night-time when NO=0) }\end{aligned}$
$\begin{aligned} & \text { Daytime background oxidant for non- } \\ & \text { episode days (by C-J method) }\end{aligned}$
$\begin{aligned} & \text { Daytime background oxidant for episode } \\ & \text { days (by C-J method) }\end{aligned}$

\section{FIGURE CAPTIONS}

Figure 1. The air quality monitoring site locations in the Greater Metropolitan Region (GMR) in New South Wales

Figure 2. Background trends from nighttime to early morning at St Marys' station when nitrogen oxide (NO) is zero, based on: (a) ozone concentration, and (b) oxidant $\left(\mathrm{Ozone}+\mathrm{NO}_{2}\right)$ concentration

Figure 3. Daytime oxidant level versus $\mathrm{NO}_{\mathrm{X}}$ in Sydney West in 1998: broken (solid) lines for episode (nonepisode) days

Figure 4. Daytime background oxidant trend for non-episode days at several Sydney sites from 1998 to 2005

Figure 5. Daytime background oxidant trend for episode days at several Sydney sites from 1998 to 2005 